\title{
PENGEMBANGAN WEBSITE PENGELOLAAN PRAKTIKUM PADA PROGRAM STUDI BIOLOGI FAKULTAS MATEMATIKA DAN ILMU PENGETAHUAN ALAM UNIVERSITAS PALANGKA RAYA
}

\author{
Widiatry ${ }^{\mathrm{a}, 1}$, Nadia Olivia Anggraini, ${ }^{\mathrm{b}, 2, *}$ \\ ${ }^{a}$ Universitas Palangka Raya, Kampus Tunjung Nyaho Jalan Yos Sudarso, Palangka Raya, Kalimantan Tengah, Indonesia \\ ${ }^{\mathrm{b}}$ Universitas Palangka Raya, Kampus Tunjung Nyaho Jalan Yos Sudarso, Palangka Raya, Kalimantan Tengah, Indonesia \\ ${ }^{1}$ widiatry@it.upr.ac.id, ${ }^{2}$ nadiaoliviaan@gmail.com \\ * corresponding author
}

ARTICLE INFO

Keywords

Biology Study Program

Waterfall

Practicum

\begin{abstract}
Learning at this time not only through materials but also by practicing. With the current manual system perceived to be inadequate such as the storage of practical student data, information about practicum. Therefore, the author builds a website to improve the practical working system with the aim of this application is to increase the efficiency of practicum.In designing the Website Praktikum Program Biology Study Faculty of Mathematics And Natural Sciences uses waterfall method with stage, Requirements Definition, System and Software Design, Implementation and Unit Testing, Integration and System Testing, Operation and Maintenance. The software used in building this website is Visual Studio Code, MySQL, and XAMPP. This website has been tested with blackbox testing that generates that every feature in the website can run well. Designing the website of praktikum biology study program faculty of mathematics and natural sciences was developed with the aim as the purpose of information media that facilitates information such as practicum schedule data, practicum modules, lists of practicum values and announcements related to practicum, can assist the head of the laboratory in monitoring the implementation of practicum.
\end{abstract}

\section{Pendahuluan}

Pemanfaatan teknologi internet digunakan untuk memfasilitasi dalam dunia perkuliahan. Teknologi dipakai agar dapat menggambarkan bagus atau tidaknya kualitas pendidikan yang didapat, karena saat ini teknologi bukan lagi merupakan suatu hal yang awam, sebab teknologi kini merupakan suatu kebutuhan manusia. Selain itu, teknologi yang diperbaharui harus tepat guna, agar apa yang dihasilkan memenuhi aspek-aspek yang diharapkan dengan adanya teknologi tersebut. Praktikum merupakan kegiatan pembelajaran yang bertujuan agar mahasiswa mendapat kesempatan untuk menguji dan mengaplikasikan atau mempraktikan teori yang telah didapatkan saat perkuliahan pada mata kuliah tertentu. Salah satu pemanfaatan teknologi internet yaitu pada kegiatan pengelolaan praktikum pada kegiatan perkuliahan. Hariyanto (2012) telah mengembangkan sistem informasi pendaftaran dan penilaian praktikum di laboratotium Teknik Informatika UPN (Universitas Pembangunan Nasional) "VETERAN" Jawa Timur menggunakan website. Pengguna sistem informasi adalah kepala laboratorium, asisten praktikum, dan praktikan. Fitur-fitur yang terdapat dalam website ini adalah pendaftaran praktikum, penilaian praktikum dan laporan nilai akhir praktikum [1].

Selama ini pelaksanaan praktikum di Program Studi Biologi Fakultas Matematika dan Ilmu Pengetahuan Alam pada Universitas Palangka Raya (UPR) masih ada beberapa kekurangan dan kelemahan, diantaranya adalah proses pelaksanaan praktikum yang masih dilakukan secara manual yaitu dengan melakukan koordinasi dari mahasiswa kepada admin bahwa akan dilaksanakan praktikum, setelah itu dilanjutkan dengan admin memberikan surat izin praktikum, mahasiswa 
mengisi surat izin praktikum kepada admin dan dibuat 2 rangkap untuk arsip laboratorium dan dosen, mahasiswa melaksanakan praktikum didampingi dosen, dan dosen menentukan nilai praktikum. Semakin banyaknya jumlah mahasiswa di Program Studi Biologi Fakultas Matematika dan Ilmu Pengetahuan Alam UPR maka pengelolaan praktikum secara manual ini mengalami banyak kesulitan terutama pada admin. Untuk mendata mahasiswa yang melakukan praktikum maka perlu dikembangkan website pengelolaan praktikum, sehingga admin tidak terlalu kesulitan dalam menangani permasalahan yang ada tersebut. Oleh karena itu dirancang dan dibuat aplikasi yang memfasilitasi untuk melakukan pengelolaan praktikum berbasis website mulai dari jadwal praktikum, tugas, informasi nilai praktikum, serta pengumuman yang berkaitan dengan praktikum.

Beberapa penelitian yang digunakan penulis untuk menambah pemahaman dalam menganalisis dan merancang suatu aplikasi berbasis website dalam melakukan pengembangan website pengelolaan praktikum di Program Studi Biologi Fakultas Matematika dan Ilmu Pengetahuan Alam UPR yaitu Rancang Bangun Website untuk Memeriksa Plagiat E-Journal Fakultas Kedokteran Universitas Palangka Raya [2], Sistem Pendukung Keputusan untuk Seleksi Penerima Beasiswa BBP-PPA dengan Metode TOPSIS berbasis Web [3], dan Rancang Bangun Website E-Learning SMAN 1 Palangka Raya [4]. Rancang Bangun Website Sistem Informasi Praktikum Jurusan Teknik Informatika Universitas Palangka Raya [5] digunakan sebagai dasar pengetahuan dalam mengembangkan website praktikum. Pengembangan Aplikasi Kartu Rencana Studi Online Pada Jurusan Pendidikan Luar Sekolah Universitas Palangka Raya [6] dan Perancangan Perangkat Lunak Pendaftaran dan Penjadwalan Ujian Skripsi Pada Fakultas Kedokteran Universitas Palangka Raya Berbasis Website [7] digunakan sebagai dasar pengetahuan dalam mengembangkan website di lingkungan Universitas Palangka Raya.

\section{Metodologi Penelitian}

Metodologi penelitian yang dilakukan menggunakan terbagi atas dua metode yaitu metode pelaksanaan dan metode pengembangan perangkat lunak.

\subsection{Metode Pelaksanaan}

Adapun metode yang digunakan dalam menyelesaikan pembuatan Website Praktikum Program Studi Biologi Fakultas Matematika Dan Ilmu Pengetahuan Alam, yaitu:

a. Metode Pengumpulan Data

Tahap pengambilan data yang berkaitan dengan permasalahan yang di bahas. Metode ini menggunakan teknik observasi, yakni pengamatan langsung terhadap program studi Biologi yang akan di teliti.

b. Metode Studi Kepustakaan

Studi Kepustakaan antara lain seperti mempelajari informasi dari internet yang memiliki kaitan dengan proses pembuatan website dan memilah kembali fitur-fitur apa saja yang cocok untuk diterapkan dalam website.

c. Metode Konsultasi

Metode konsultasi merupakan proses tanya jawab atau bimbingan dan diskusi kepada dosen pembimbing mengenai website yang di buat sehingga ditemukan arah seperti apa website nantinya.

d. Metode Implementasi

Metode ini di mana mulai melakukan proses pengerjaan website dengan data yang sudah dikumpulkan dan dirancang sedemikian rupa.

\subsection{Metode Pengembangan Perangkat Lunak}

Metode yang digunakan dalam pembuatan website ini adalah metode waterfall, metode ini pertama kali dikenalkan oleh Winston Royce pada tahun 1970, metode ini dipilih karena mempunyai struktur yang lebih terarah baik itu dalam setiap perancangan maupun implementasinya sehingga dengan berbagai pertimbangan kualitas sistem yang dihasilkan akan lebih baik [8]. Rancangan penelitian yang dibuat terdiri atas dua tahap yaitu: (1) pengumpulan 
dan analisis data yang dilakukan dengan cara studi pustaka dan observasi, (2) menerapkan metode waterfall [9] yang sudah dimodifikasi dengan tahap-tahapnya adalah analisis sistem, desain, implementasi dan pengujian. Selanjutnya pada tahapan testing menggunakan metode Blackbox [10][11][12].

Dibawah ini pada gambar 1 merupakan metode waterfall yang digunakan:

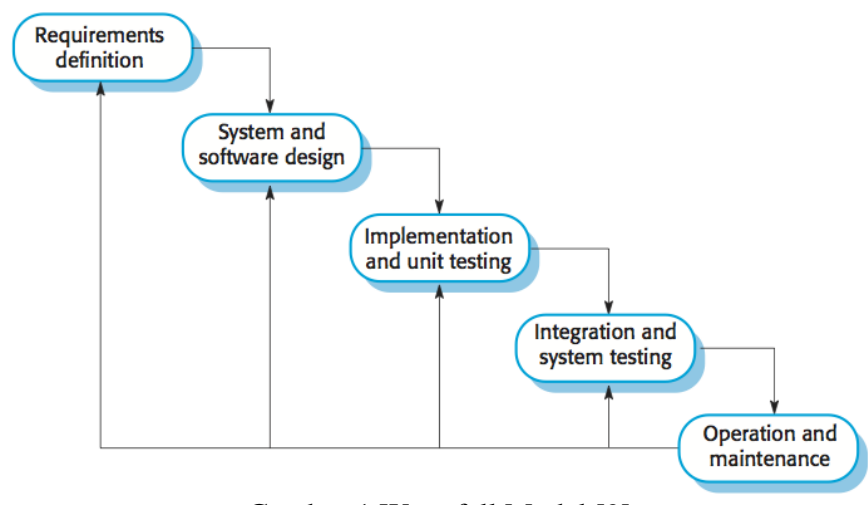

Gambar 1 Waterfall Model [9]

Dimana pada metodologi waterfall ini terdapat beberapa tahapan yaitu :

a. Requirements Definition (Definisi Kebutuhan)

b. System dan Software Design (Desain Sistem dan Software)

c. Implementation and Unit Testing (Implementasi dan pengujian unit)

d. Integration and System Testing (Integrasi dan Pengujian Sistem)

e. Operation and Maintenance (Operasi dan Pemeliharaan)

\section{Hasil dan Pembahasan}

\subsection{Perancangan Sistem}

a. Diagram Konteks

Dibawah ini pada gambar 2 merupakan diagram konteks: 
Jim

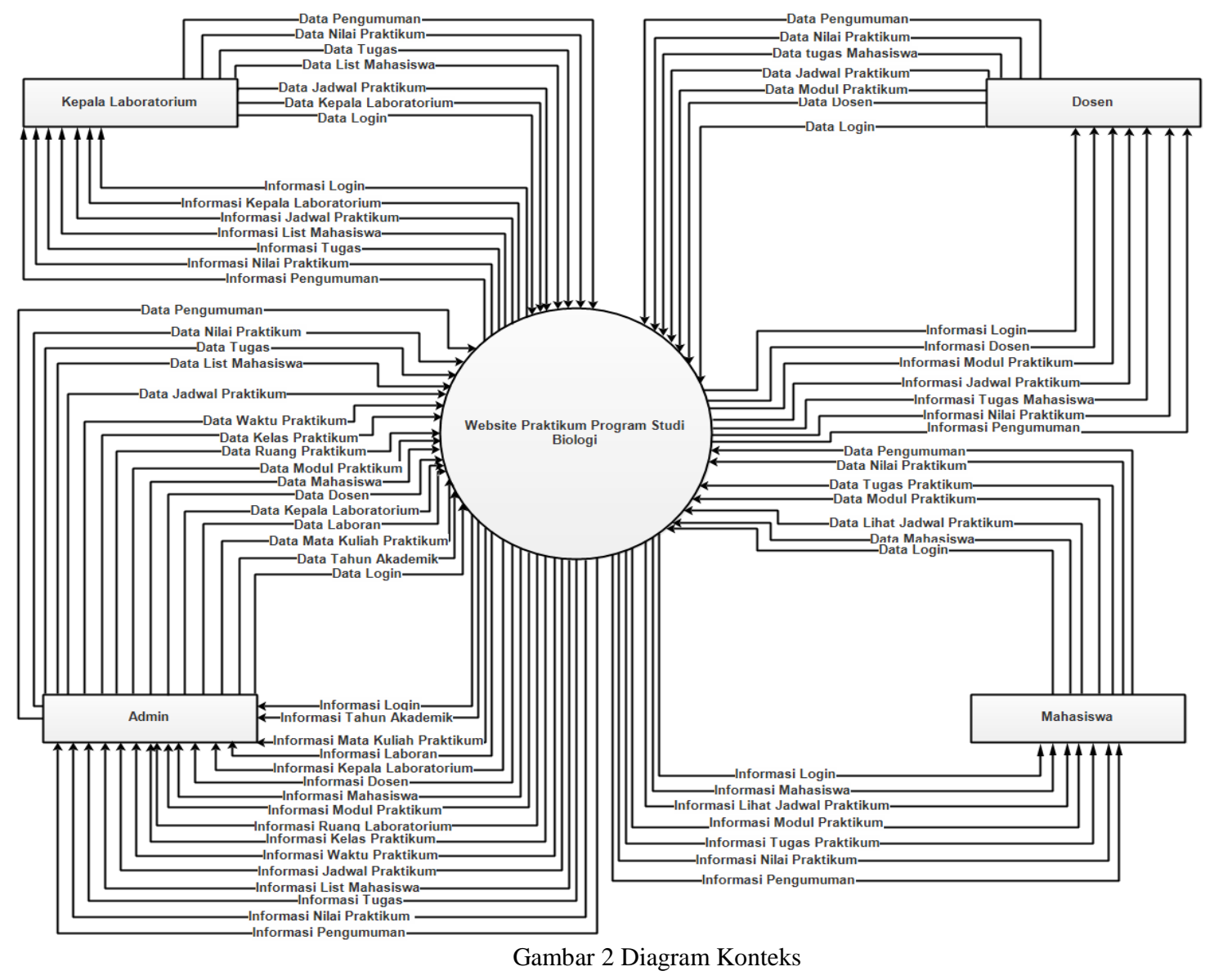

b. Data Flow Diagram

Dibawah ini pada gambar 3 merupakan Data Flow Diagram: 


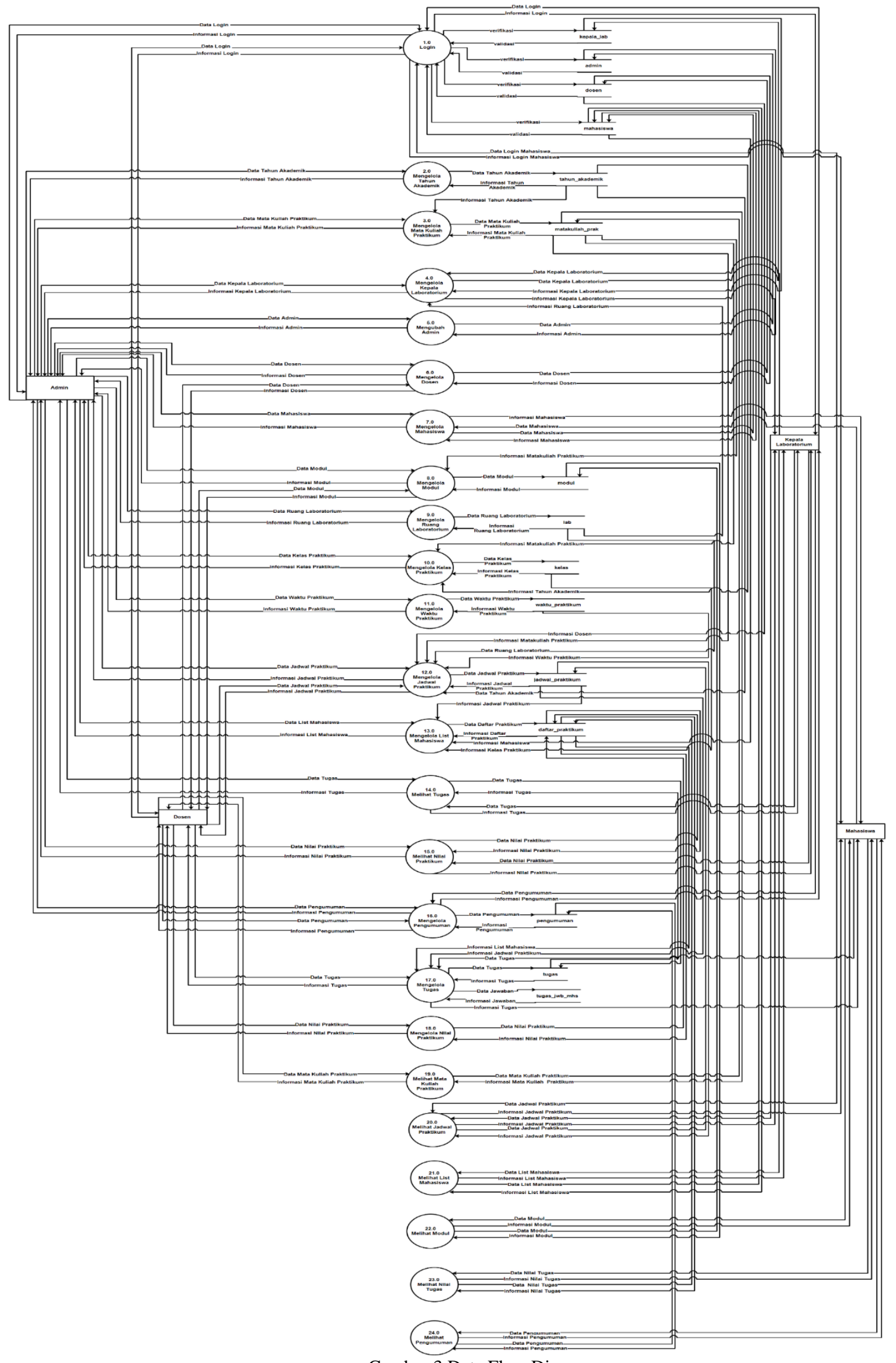


c. Entity Relationship Diagram

Dibawah ini pada gambar 4 merupakan Entity Relationship Diagram dari :

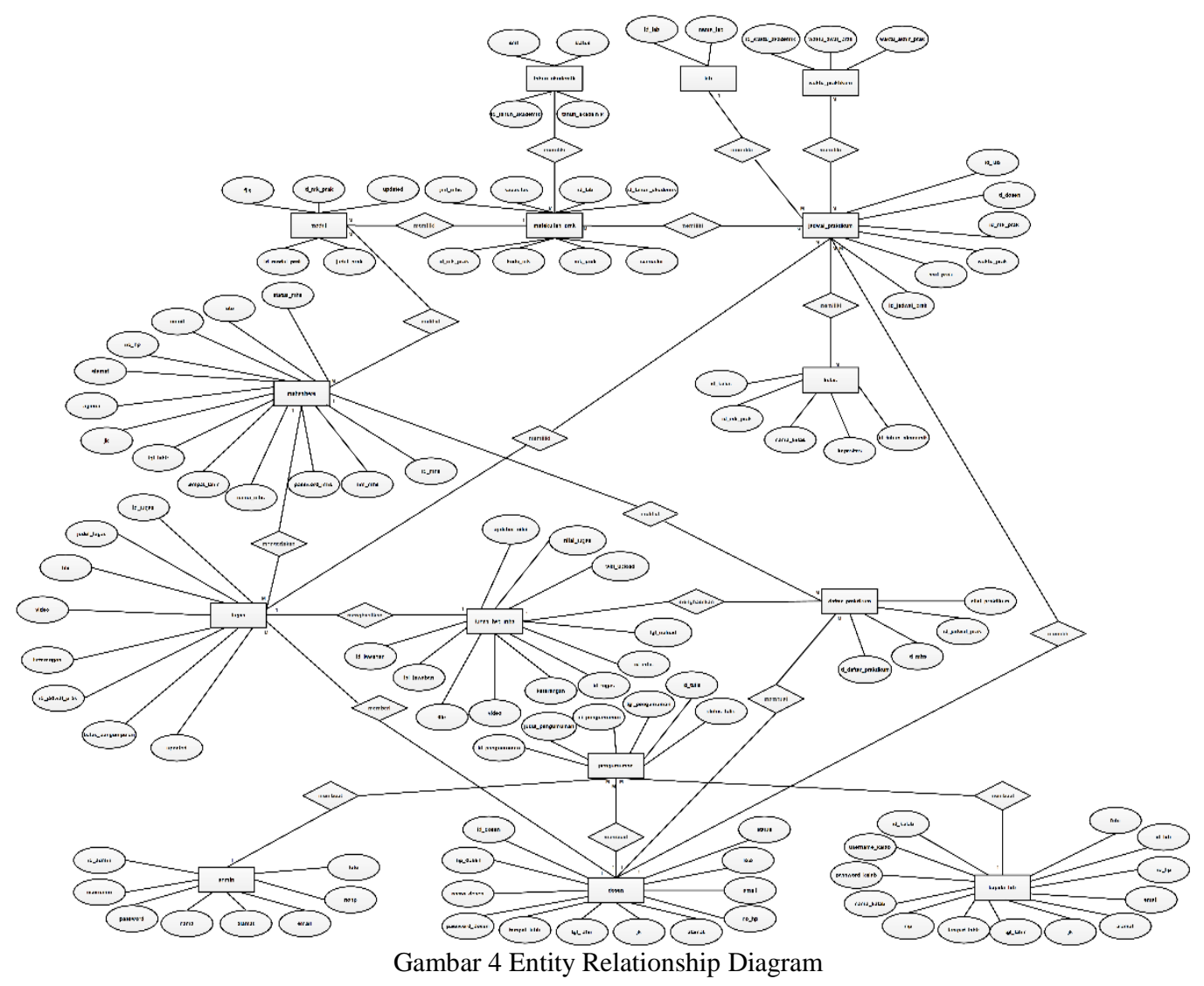

3.2 Perancangan Desain Sistem

a.Halaman Login

Di bawah ini pada gambar 5 merupakan tampilannya: 

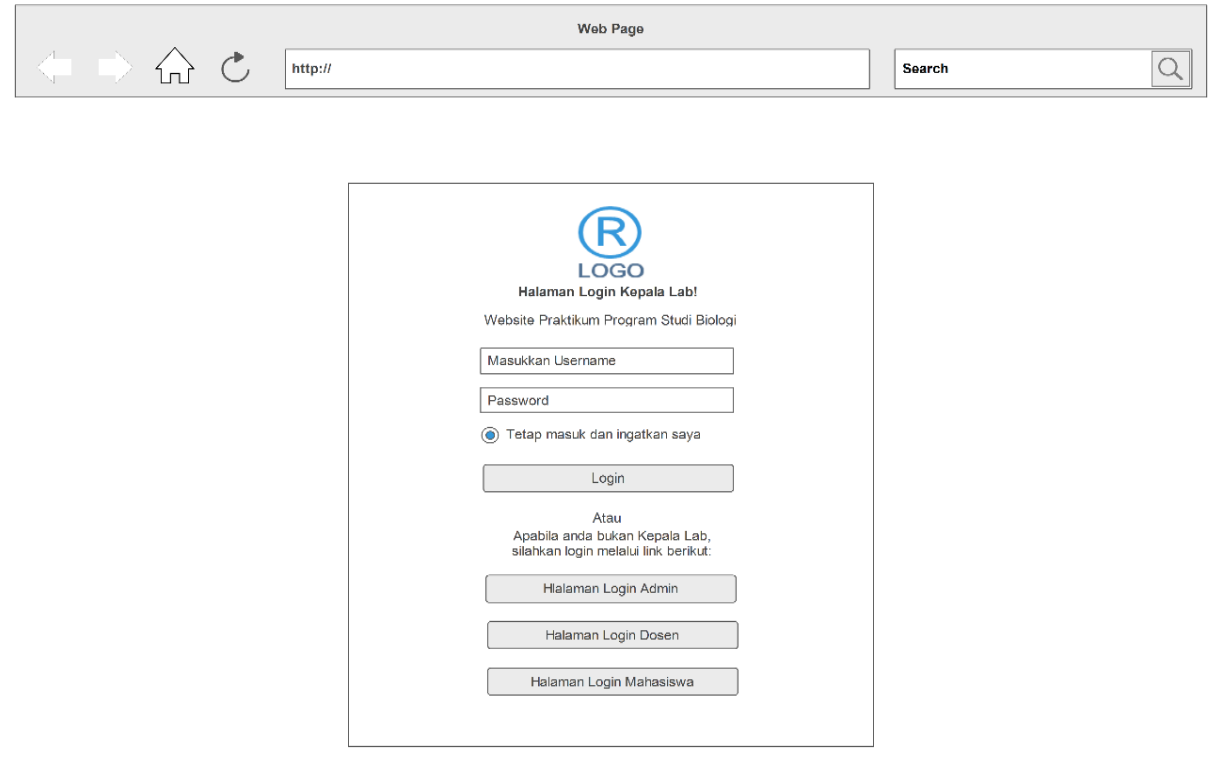

Gambar 5 Halaman Login

d. Halaman Dashboard Kepala Laboratorium

Di bawah ini pada gambar 6 merupakan tampilannya:

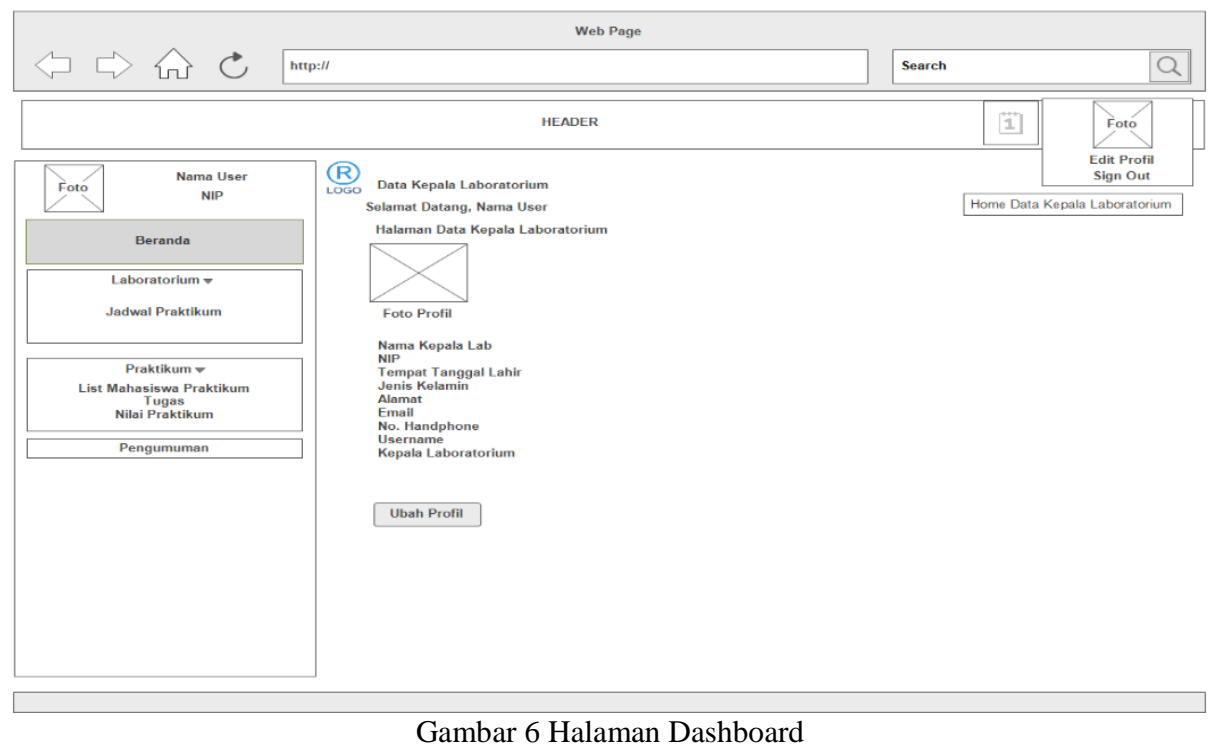

e. Halaman Dashboard Admin

Di bawah ini pada gambar 7 merupakan tampilannya: 


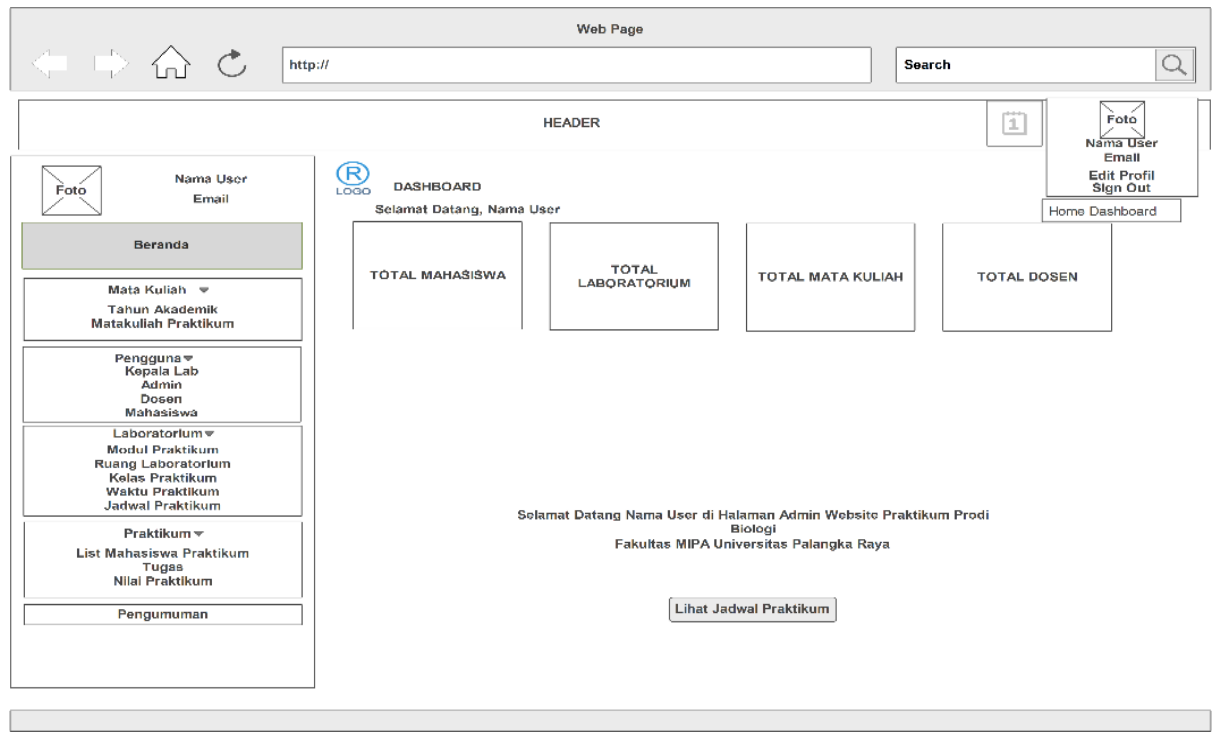

Gambar 7 Halaman Admin

f. Halaman Dashboard Dosen

Di bawah ini pada gambar 8 merupakan tampilannya:

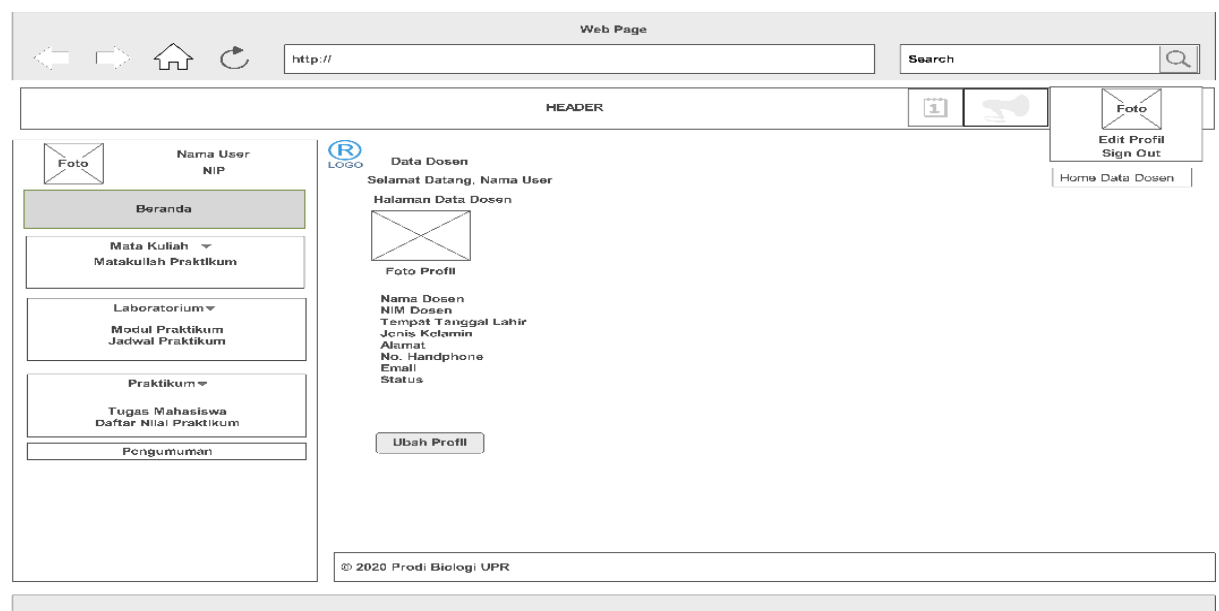

Gambar 8 Halaman Dosen

g. Halaman Dashboard Mahasiswa

Di bawah ini pada gambar 9 merupakan tampilannya: 




Gambar 9 Halaman Mahasiswa

\subsection{Hasil Tampilan Sistem}

a. Halaman Login

Di bawah ini pada gambar 10 merupakan tampilannya:
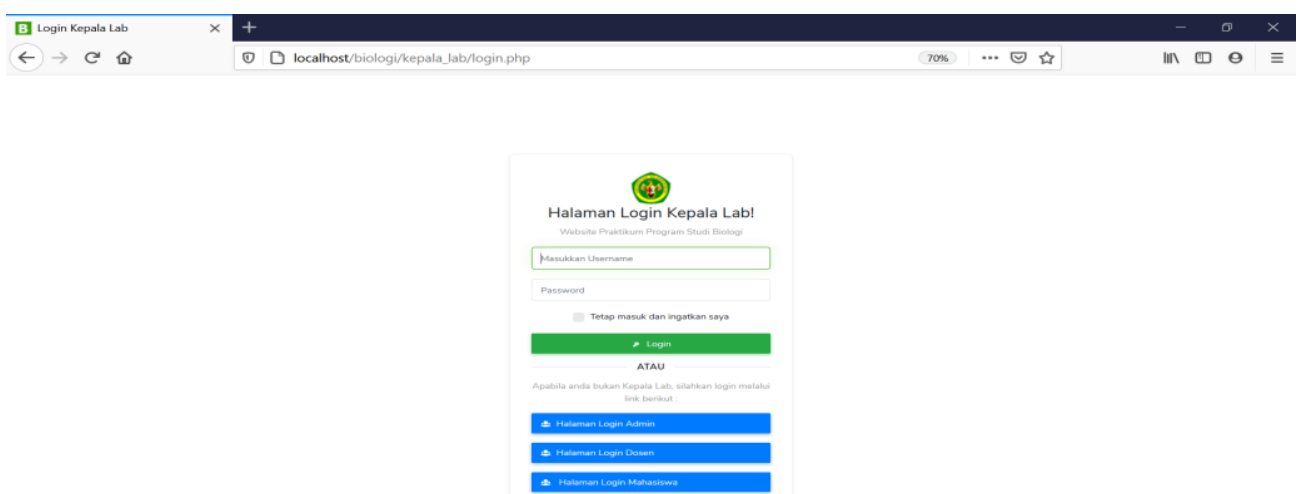

h. Halaman Beranda Kepala Laboratorium

Gambar 10 Halaman Login

Di bawah ini pada gambar 11 merupakan tampilannya:

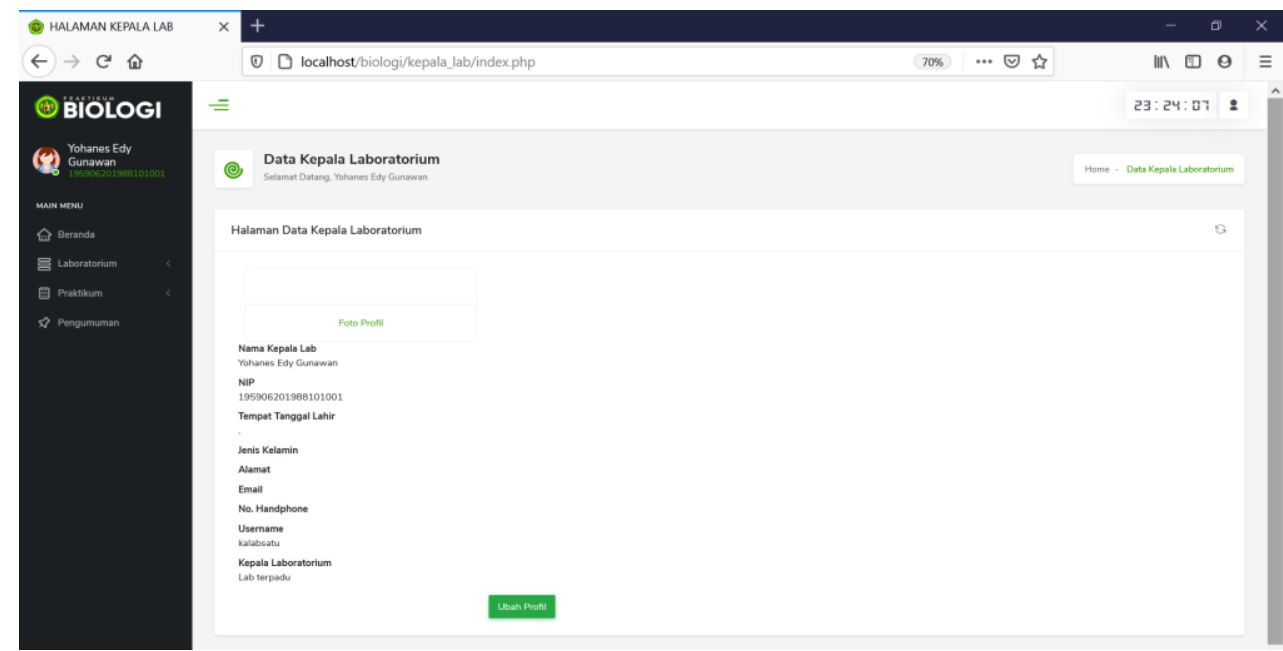

Gambar 11 Halaman Beranda Kepada Laboratorium 
i. Halaman Beranda Admin

Di bawah ini pada gambar 12 merupakan tampilannya:

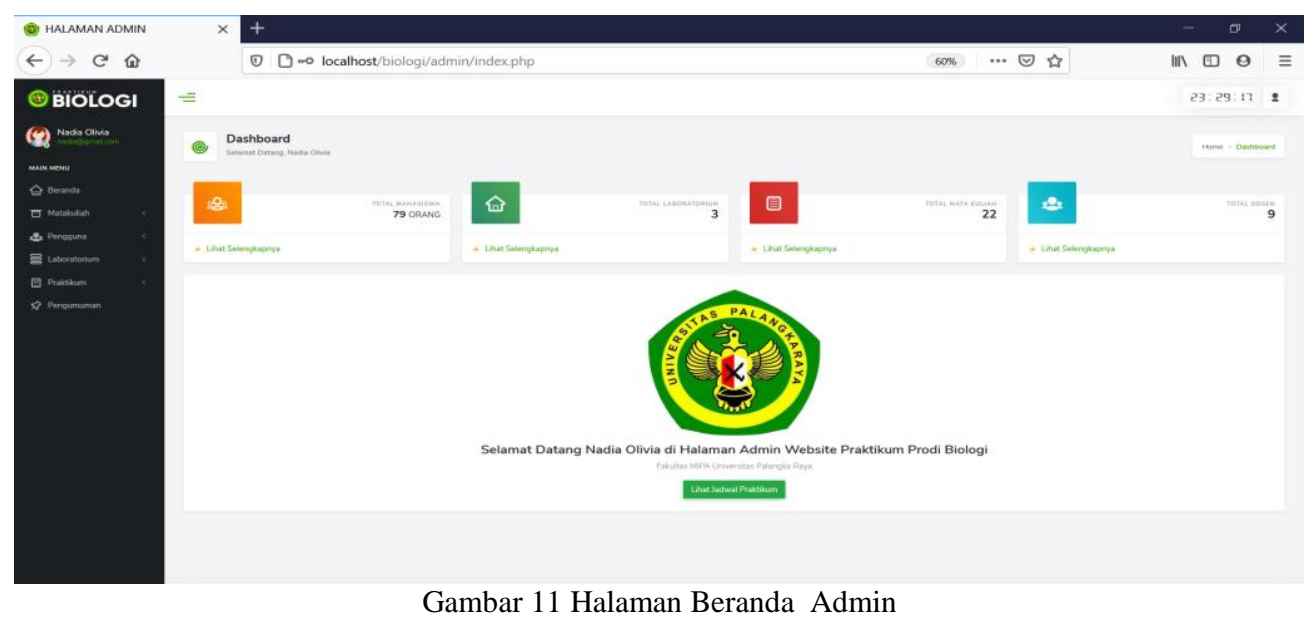

j. Halaman Beranda Dosen

Di bawah ini pada gambar 13 merupakan tampilannya:

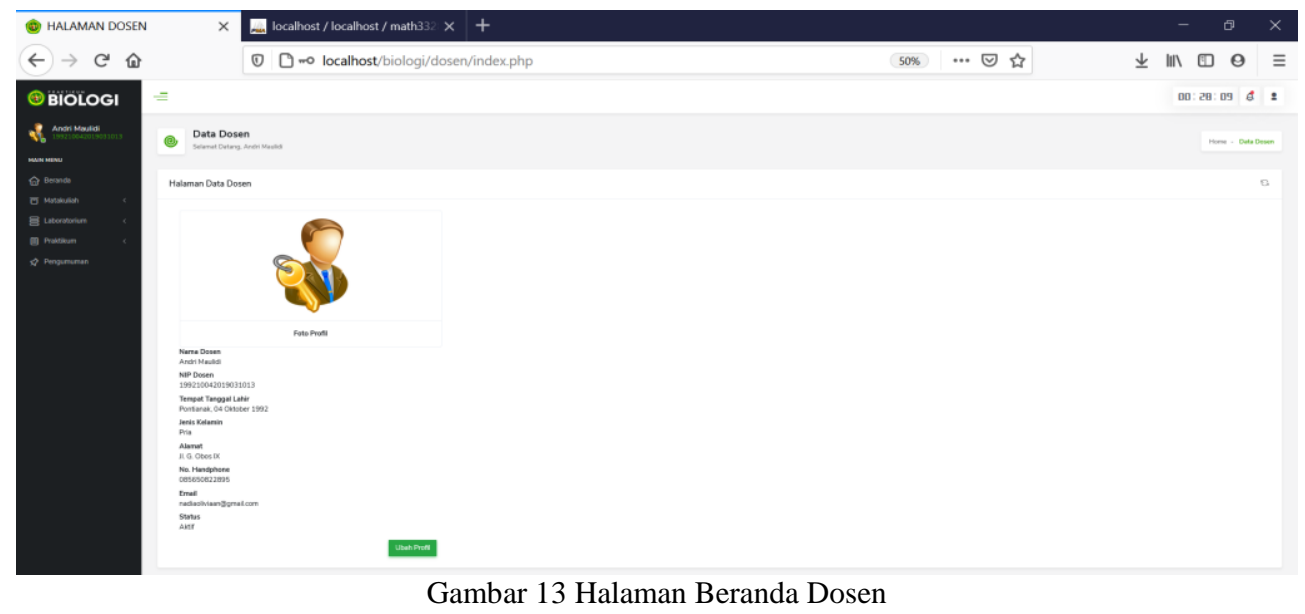

k. Halaman Beranda Mahasiswa

Di bawah ini pada gambar 11 merupakan tampilannya: 


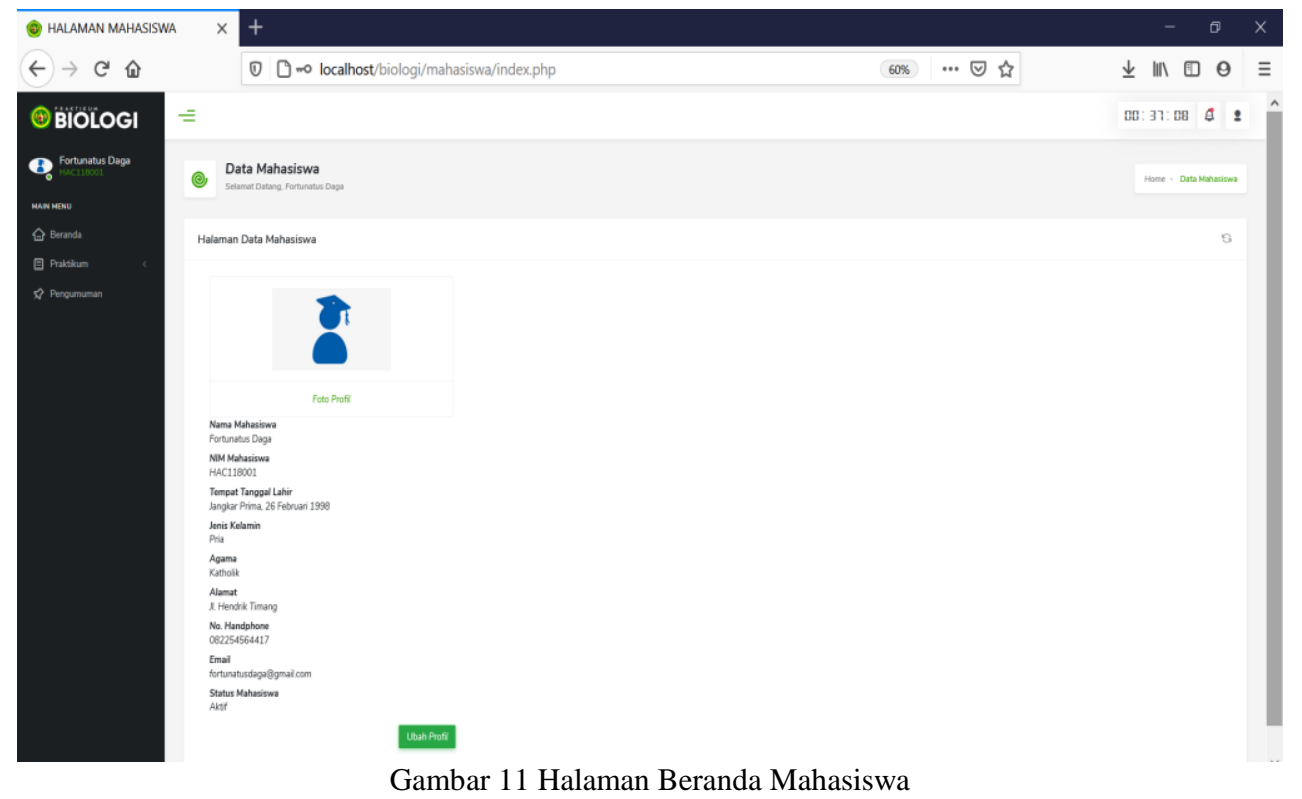

\section{Kesimpulan}

Dari penelitianyang telah dibuat dengan judul "Rancang Bangun Website Praktikum Program Studi Biologi Fakultas Matematika Dan Ilmu Pengetahuan Alam" dapat disimpulkan bahwa:

Dalam merancang dan membangun website ini menggunakan metodologi pengembangan perangkat lunak Waterfall Menurut Summerville tahun 2011, yang memiliki tahapan yaitu requirements definition yang dilakukan dalam pembuatan perancangan bisnis proses dan flowchart. System and software design dilakukan dalam pembuatan Data Flow Diagram (DFD) dan Enity Relationship Diagram (ERD), dan desain interface. Implementation and unit system dengan bahasa pemrograman yang digunakan yaitu HTML, PHP, CSS, Bootstrap, Javascript dan $M y S Q L$ dan. Integration and system testing metode testing yang digunakan pada pembuatan Web ini adalah metode Blackbox. Dari hasil pengujian ini dapat disimpulkan bahwa Website ini dapat berjalan sesuai dengan fungsi. Website ini secara umum mempergunakan proses pengolahan manajemen database yaitu dari sisi kepala laboratorium berupa manajemen data laboratorium,data praktikum dan data pengumuman praktikum. Pada sisi admin berupa manajemen data matakuliah, data pengguna, data laboratorium, data praktikum, dan data pengumuman. Pada sisi dosen berupa data matakuliah, data laboratorium, data praktikum dan data pengumuman. Pada sisi mahasiwa berupa data jadwal, modul, tugas nilai dan data pengumuman.

Adanya website Praktikum Program Studi Biologi Fakultas matematika dan Ilmu Pengetahuan Alam ini akan memfasilitasi kepala laboratorium, admin, dan dosen untuk mengelola dan juga untuk mahasiswa dalam informasi tentang praktikum.

\section{Daftar Pustaka}

[1] Hariyanto, Rakhmad Satriya. (2012). Sistem Informasi Pendaftaran dan Penilaian Praktikum Di Laboratorium Teknik Invormatika UPN "VETERAN" JATIM. Universitas Pembangunan Nasional "VETERAN". Surabaya.

[2] Widiatry, W. \& Sari, N. N. K., (2019). Rancang Bangun Website untuk Memeriksa Plagiat EJournal Fakultas Kedokteran Universitas Palangka Raya. Jurnal CoreIT 5(2), 36-43.

[3] Sari, N. N. K., Widiatry, W., \& Chitayae, N. (2018). Sistem Pendukung Keputusan untuk Seleksi Penerima Beasiswa BBP-PPA dengan Metode TOPSIS berbasis Web. Anterior Jurnal, 18(1), 86-91. 
[4] Widiatry, W. \& Nugraha, A. (2018). RANCANG BANGUN WEBSITE E-LEARNING SMAN 1 PALANGKA RAYA. JURNAL TEKNOLOGI INFORMASI, 12(1), 57-62.

[5] Widiatry, W. (2017). Rancang Bangun Website Sistem Informasi Praktikum Jurusan Teknik Informatika Univeritas Palangka Raya. Jurnal SAINTEKOM, 6(2), 12-24.

[6] Widiatry, W. (2020). PENGEMBANGAN APLIKASI KARTU RENCANA STUDI ONLINE PADA JURUSAN PENDIDIKAN LUAR SEKOLAH UNIVERSITAS PALANGKA RAYA. JURNAL TEKNOLOGI INFORMASI, 14(1), 83-93.

[7] Widiatry, W. (2020). PERANCANGAN PERANGKAT LUNAK PENDAFTARAN DAN PENJADWALAN UJIAN SKRIPSI PADA FAKULTAS KEDOKTERAN UNIVERSITAS PALANGKA RAYA BERBASIS WEBSITE. JURNAL TEKNOLOGI INFORMASI, 14(2), 150-160.

[8] Royce, Winston. (1970). Managing the Development of Large Software Systems, Proceedings of IEEE WESCON 26 (August): 1-9.

[9] Pressman, S. Roger. (2010). Pendekatan Praktisi Rekayasa Perangkat Lunak. Edisi 7. Penerbit Andi. Yogyakarta. Halaman 45-46.

[10] Widiatry, W., Sari, N. N. K., Pranatawijaya, V. H., \& Putra, P. B. A. A. (2019). Penerapan Algoritma Levenshtein Distance Untuk Pencarian Pada Sistem Informasi Perpustakaan Fakultas Kedokteran Universitas Palangka Raya. Jurnal SAINTEKOM, 9(1), 66-82.

[11] Putra, P. B. A. A., Pranatawijaya, V. H., Widiatry, W., \& Sari, N. N. K., (2019). Pengembangan Perangkat Lunak Generate File Data Kehadiran Pegawai Universitas Palangka Raya. Anterior Jurnal,18(2), 182-189.

[12] Putra, P. B. A. A., Pranatawijaya, V. H., Widiatry, W., \& Natalius, N. (2018). Analisis dan Desain Perangkat Lunak Generate File Akun Uang Kuliah Tunggal (UKT) Universitas Palangka Raya. JURNAL TEKNOLOGI INFORMASI, 12(1), 42-49. 